Original Research Article

\title{
A study on drug induced cutaneous adverse drug reactions at a tertiary care hospital, Mysore, India
}

\author{
Kishore M. S.*, Shashikala S. Konnur
}

Department of Pharmacology, Mysore Medical College and Research Institute, Mysore, Karnataka, India

Received: 21 January 2019 Accepted: 05 March 2019

*Correspondence to:

Dr. Kishore M. S.,

Email: shashikalakonnur@ gmail.com

Copyright: (C) the author(s), publisher and licensee Medip Academy. This is an openaccess article distributed under the terms of the Creative Commons Attribution NonCommercial License, which permits unrestricted noncommercial use, distribution, and reproduction in any medium, provided the original work is properly cited.

\begin{abstract}
Background: Drugs, however safe and efficacious, are associated with risk of adverse reactions. Adverse Drug Reactions (ADRs) are one of the leading causes of morbidity and mortality. ADRs was rated as the fifth leading cause of death among all diseases. Consequences of ADRs range from diminished quality of life, increased physician visits, hospitalizations, and even death. The objectives of the study were to obtain information about drug induced cutaneous adverse reactions and to establish the causal relationship.

Methods: Observational cross sectional study, a total of 76 patients were recruited for the study,conducted in dermatology outpatient department of K R Hospital Mysore Medical College And Research Institute Mysore for 3 months. The drug reactions were recorded in ADR form of Central Drugs Standard Control Organisation (CDSCO). Causality was assessed using Naranjo algorithm and World Health Organization- Uppsala monitoring centre (WHO-UMC) criteria.

Results: 76 patients with CADRs were included in the study during the 3 months study period. Most common age group with CADRs was 20-30 years; with $55.73 \%$ of females $20.26 \%$ male and the most common suspected drug group causing CADRs was antimicrobial $35.46 \%$. And most common lesion is maculopapular rashes. According to Naranjos scale $67.30 \%$ of CADRs were probably caused by drugs.

Conclusions: variety of drugs causes CADRs. Awareness among clinicians is required for active reporting of CADRs. Patients need to be educated for the cautious use of drugs causing ADRs to prevent the same.
\end{abstract}

Keywords: Cutaneous adverse drug reactions, Naranjos probability scale, Pharmacovigilance, Post-marketing surveillance

\section{INTRODUCTION}

Drugs, no matter how safe and efficacious, are coupled with in escapable risk of adverse reactions. Adverse Drug Reactions (ADRs) are considered as one among the leading causes of morbidity and mortality. ${ }^{1}$ An 'adverse drug reaction', as defined by the World Health Organization, is a noxious, unintended effect of a drug, which occurs at normal doses in humans for the prophylaxis, diagnosis, or the therapy of the disease or for the modification of its physiological function. ${ }^{2}$
Dermatological conditions are common in clinical practice accounting for up to $2 \%$ of consultations in general practice worldwide. Cutaneous ADRs are the commonest ADRs $(30-45 \%)$ and are responsible for about $2 \%$ of hospital admissions. Approximately $2-7 \%$ of these may be severe. The incidence of dermatological ADRs among inpatients in developed countries ranges from 1-3\% whereas in developing countries such as India it is $2-5 \%$ Approximately $5-8 \%$ of all hospitalization worldwide is due to adverse drug reactions. ${ }^{3}$ 
The pattern of skin disease varies from one country to another and across different parts within the same country. ${ }^{4}$ In India the most prevalent dermatological condition include scabies, pyoderma, dermatitis, urticaria, fungal skin infection, acne, alopecia and less common are eczematous disorder like psoriasis, skin cancer and cutaneous adverse drug reaction. ${ }^{5}$ The pattern of cutaneous reactions differs among various drugs. Hence, understanding the precise nature of CADR may help narrow down the search for the offending agent. Knowledge of drugs that can cause CADR can help physicians in choosing safer drugs and therefore can be helpful to society at-large, early detection, evaluation and monitoring of ADR are essential to reduce harm to patients and thus improve public health. ${ }^{6,7}$

Thus, this present study is designed to obtain information about drug induced cutaneous adverse reactions and assessing the causality of the drug and adverse reactions by using various scales.

\section{METHODS}

The study was approved by the Institutional Ethics Committee. Patients with drug induced adverse reactions attending dermatology Out Patient Department, K R Hospital, Mysore Medical College and Research Institute Mysore, from June to August 2017.

It was an observational cross sectional study of drug induced cutaneous adverse drug reactions which were reported at Dermatology Department K R Hospital Mysore Medical College Research Institute Mysore during 3 months period was evaluated. The details of CADRS were recorded in ADR form of Central Drugs Standard Control Organization (CDSCO). Causality was assessed using Naranjo algorithm and also with causality assessment of scale as per World Health Organization- Uppsala monitoring centre (WHO-UMC) criteria.

\section{Inclusion criteria}

Patients following criteria were included in the study:

- Those in which the diagnosis of the cutaneous adverse reaction was in accordance with the definition of ADRs which was provided by the WHO

- Those in which there was no alternate explanation for the reaction.

- Those in which there was a plausible time relationship between the introduction of the drug and the onset of a reaction.

- Those in which there was improvement in the condition of the patient after dechallenge/withdrawal of the suspected drug.

\section{Exclusion criteria}

- Subjects who complained of only symptoms (e.g., itching) without visible skin lesions
- $\quad$ Those who could not recall the name of the suspect medicines consumed, and those whose lesions turned out to be disease related (e.g., viral exanthems, rash of rickettsia infections, and collagen vascular disease) on closer examination.

- $\quad$ Subjects who reported to have consumed indigenous (ayurvedic and homeopathic) medicines were also excluded as the herbal ingredients could not be identified in their case.

\section{Statistical analysis}

The ADR'S were assessed using Naranjo algorithm and also with causality assessment of scale as per World Health Organization- Uppsala monitoring centre (WHO-UMC) criteria.

The descriptive statistical analysis has been carried out to find the sex, age, pharmacological, class wise distribution of the adverse drug reactions. The total number of particular reactions was also calculated. All the data have been expressed in terms of percentage and analysis was done using $\mathrm{R}$ - software $20^{\mathrm{TH}}$ version.

\section{RESULTS}

In the current study 76 patients were assessed for CADRS for 3 months of period.

\section{Demographics}

Majority of patients were in the age group of 20-30 years $(44.73 \%)$, with a mean age of 24.99 years (Table 1 ).

Table 1: Age distribution of CADR.

\begin{tabular}{|lll|}
\hline Age & Total no. of CADR & Percentage \\
\hline$<20$ yrs & 15 & $19.73 \%$ \\
\hline $20-30$ yrs & 34 & $44.73 \%$ \\
\hline $30-40$ yrs & 15 & $19.73 \%$ \\
\hline$>40$ & 12 & $15.78 \%$ \\
\hline
\end{tabular}

Out of 76 patients studied,55 (73.32\%) were female and 21 (26.88\%) were male patients (Table 2). In present study there was a female preponderance over the male patients.

Table 2: Sex distribution of CADR.

\begin{tabular}{|lll|}
\hline Sex & Total no ADR & Percentage \\
\hline Male & 21 & 26.68 \\
\hline Female & 55 & 73.32 \\
\hline
\end{tabular}

Most frequently encountered drugs causing CADRS Antibiotics 36 (47.36\%), Steroids 18 (23.88\%), NSAIDS16 (21.05) and in others 6 (7.80) it includes Anticonvulsants, contracts dyes, antihypertensives (Table 3). The current study showed that, according clinical observations. Distribution of types of CADRS caused by drugs maculopapular lesions $(39.47 \%)$ and followed by 
with visible rash $(27.63 \%)$, photosensitivity $(23.68 \%)$ and angioedema $(9.21 \%)$ showed in the Figure 1.

Table 3: Drugs causing CADRs.

\begin{tabular}{|lll|}
\hline Pharmacological class & $\begin{array}{l}\text { NR of } \\
\text { ADR }\end{array}$ & $\begin{array}{l}\text { Percentage } \\
\text { of ADR }\end{array}$ \\
\hline Steroids & 18 & $23.88 \%$ \\
\hline Antibiotics & 36 & $47.36 \%$ \\
\hline NSAIDS & 16 & $21.05 \%$ \\
\hline Others & 6 & $7.80 \%$ \\
\hline
\end{tabular}

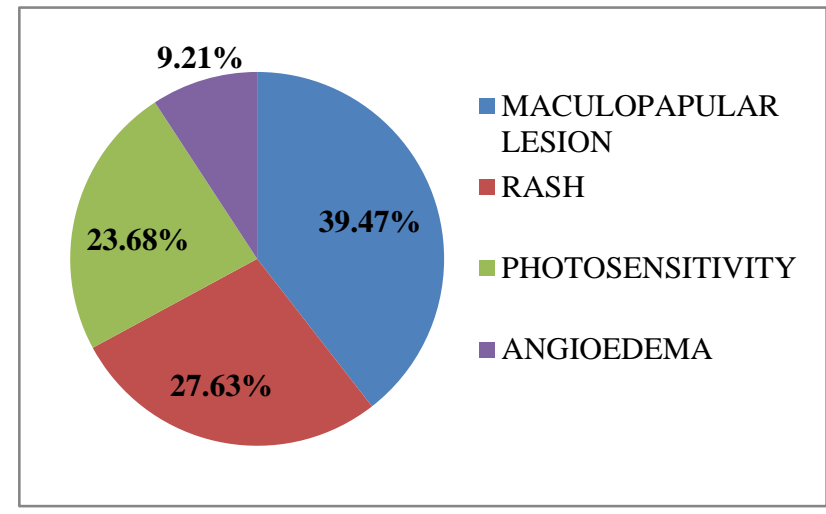

Figure 1: Distribution of types of CADRs caused by drugs.

In this present study it showed frequency of distribution of drugs causing reactions, most commonly it was seen with antibiotics $(47.36 \%)$, steroids $(23.68 \%)$, NSAIDS $(21.05 \%)$ and others (contrast dye, antihypertensive, anticonvulasnts) (7.8\%) (Figure 2).

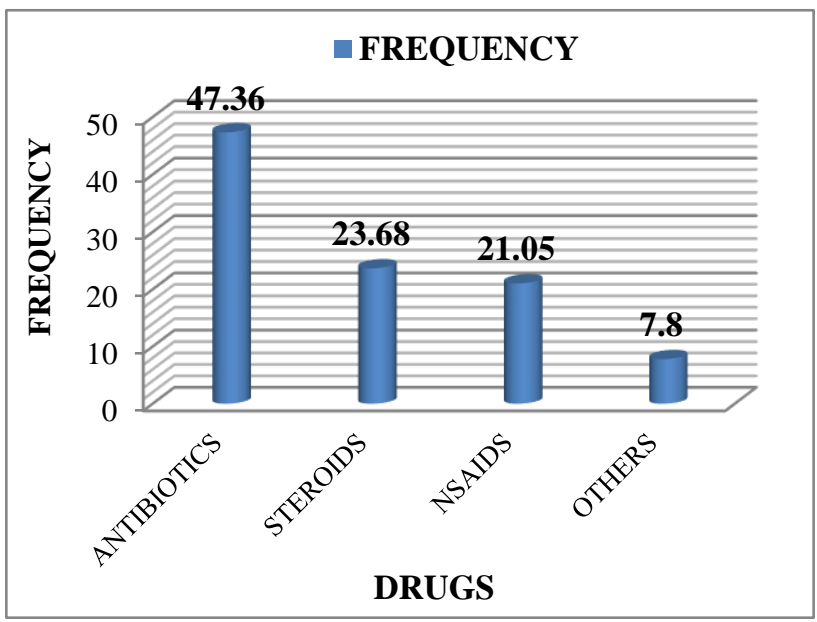

Figure 2: Distribution of drugs causing CADRs.

Current study assessed the CADRs by using WHO-UMC scale according to that scale $67 \%$ of reactions were probable, $29 \%$ possible, and $4 \%$ definite (Figure 3 ).

In this study it showed $67.4 \%$ proable, $28.6 \%$ possible, $4 \%$ definite reactions occurred by Naranjo scale of causality preventability assessment scale (Figure 4).

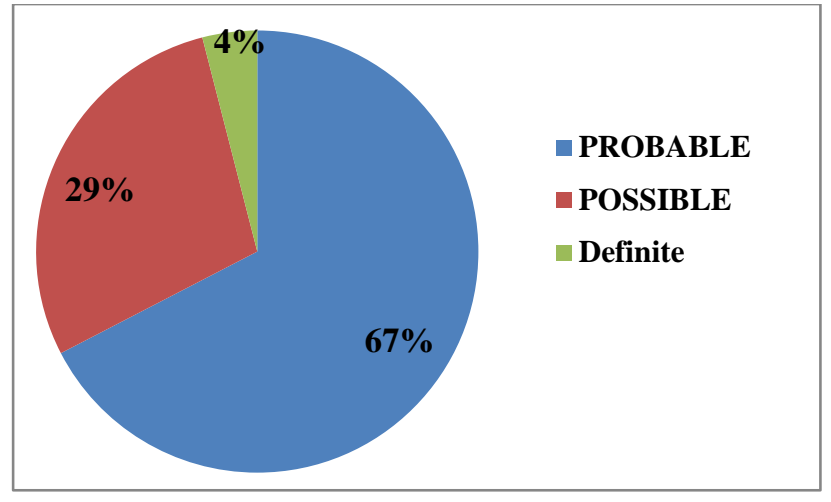

Figure 3: Assessment of percentage drugs causing CADRs by WHO-UMC scale.

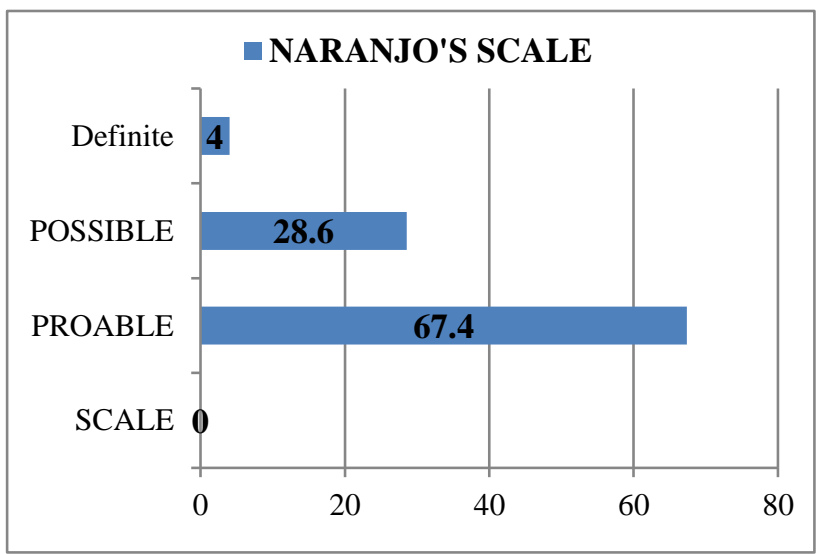

Figure 4: Naranjo scale of causality assessment.

\section{DISCUSSION}

Cutaneous reactions are most common type reactions to occurs with drugs. Which ranging from maculopapular rashes to toxic epidermal necrolysis can be produced by various drugs which is commonly prescribed by treating patients from treating physicians and also by availability of over the counter medicine. ${ }^{8}$ Some severe CADRs may results in serious morbidity causing increased length of stay at hospital and causing economic burden for patient as well as family and even death due to serious life treating reactions. $^{9}$

In the present study, a total of 76 CADRs were reported. This number may not represent the true prevalence of occurrence of CADRs. During study period as patients with incomplete history and doubtful diagnosis were excluded from the study. Moreover, the exclusion of many minor cutaneous reactions which do not require hospitalisation and underreporting by patients might have contributed to the decreased prevalence in this study. ${ }^{7}$

In this study we found that major age group who presented with CADR in between the age groups 20-30 years $(44.73 \%), 30-40$ years $(19.73 \%)$ and younger age group below 20 years of age (19.73\%) affected with drug reactions and least onset of adverse reaction occurred 
above the age of 40 years (15.78\%).This difference of results were because of more co morbities starts appearing like hypertension and diabetes mellitus patients will not take unnecessary medications without doctor supervision.

Majority of ADR's in this study was occurred in females $(73.32 \%)$ than compared to males $(26.68 \%)$. The same outcome was found in some studies having female majority of onset Nandha R, Gupta A, and Hashmi A and Pudukadan D, Thappa DM. ${ }^{8,10}$

This difference is due to females are more beauty conscious about cutaneous reactions occurrence and they report it doctors compared to men's who neglect it and thinks as its minor reactions and failed to report it. Male predominance also seen in some of the studies Ames $\mathrm{J}$, Sushma M, Gudio S et al. ${ }^{11}$ And age group of onset of adverse cutaneous reactions was found similar with others study Lamani VL, Ratnakar JS et al. ${ }^{12}$

Drugs can cause variety of ADR's with different in their morphology and distribution in the various parts of the body. In this study it showed that, most common cutaneous reaction occurred, Maculopapular rash $(39.47 \%)$, followed with rash (27.63\%), Photosensitivity (23.68\%), and Angioedema $(9.21 \%)$ this was due to most of drugs were taken from over the counter availability of some of antibiotics and without giving proper instructions to the patients. which found similar with other study Sushma M, Noel MV, Ritika MC et al, and Verma R, Tiwari S, Gupta CM, Verma N. ${ }^{9,13}$

Drugs causing maximum CADR in this study is with Antibiotics $(47.36 \%)$, followed by Steroids (23.88\%), NSAIDS (21.05\%), and others group includes Antiepileptic, CVS drugs and comparing our study results with others studies same results were obtained that is fixed drug eruption was caused by antibiotics and steroids Lamani VL, Ratnakar JS et al, and N Luigi, Conforti A, et al. ${ }^{12,14}$

In this study we have used two scales for assessing causality and prevention scale, where it tells about exact cause of reactions whether it is because of drug or underlying disease or other factors, and also to establishes the relationship between the occurrence of reaction and time gap of intake of drugs.

Out of 76 patient's in this study it showed that $67 \%$ reactions were classified into Proable, 29\% Possible, and remaining as Unassessed (4\%) based on WHO-UMC scale that indicates most of reactions were occurred because of drugs only, reactions were disappeared with stoppage of drug but we have not ruled out exact cause of reaction and laboratory tests were not being conducted. And it showed $67.4 \%$ proable, $28.6 \%$ possible, $4 \%$ definite reactions occurred by Naranjo scale of which was found more similar with others studies Verma R, Tiwari S, Gupta CM et al, and Borah A, Lahkar M, Singha B. ${ }^{13,15}$

\section{CONCLUSION}

CADRS are reactions which are potentially preventable reactions by consulting right doctor at right time and for right durations of treatment. Doctors can also prevent this reactions occurrence by prescribing right drug to right patient by knowing proper drug interactions and selecting it based on need of the patients.

In this study we focused on the pattern of dermatological cutaneous adverse reactions of a drug class in post marketing surveillance studies to find out variety of adverse reactions occurred due to drugs. ADRS may vary from rash to angioneurotic edema where it requires immediate treatment and withdrawal of offending drug with hospitalization of the patient.

This difference in distribution of various drugs causing reaction was due to patients needs more symptomatic treatment than cure because of that prescribers use "pill for every illa" policy and uses antibiotics for almost all the illness, and availability of steroids, because of steroid property of all inflammatory conditions and presence of tropical forms of steroids which makes skin whitening girls are more attracted for this and develops ADR's with this.

And if patient failed follow up specially having seizures and starts taking drugs with same prescriptions for long periods may end up with ADR'S.

ADR's are assessed by using various scale so that, easy identify and prevention of these types of reactions further occurring in future and helpful for reducing its occurrence causing severe burden to the society and family causality assessment that means most of reactions were preventable if we take proper measures to reduce the incidence of reactions by making restrict rule of not using over the counter drug and avoiding pill for every ill policy.

Thus by preventing unnecessary occurrence of reactions causing socio economic burden to patients and society and increasing morbidly and mortality of the person.

Funding: No funding sources

Conflict of interest: None declared

Ethical approval: The study was approved by the Institutional Ethics Committee

\section{REFERENCES}

1. Ghosh S, Acharya L, Rao P. Study and evaluation of various cutaneous adverse drug reactions in kasturba hospital, Manipal. Indian J Pharm Sci. 2006 Mar;68(2):212-5.

2. Edwards IR, Aroson JK. Adverse drug reactions: Definitions, diagnosis and management. Lancet. 2000;356:1255-6.

3. Sajith M, Lokhande KD, Padma S, Pawar AP. Prevalence of various skin disorders and prescribing 
pattern of antihistamines in tertiary care hospital, Pune. Int J Phar Scien Resea. 2014;5(03):73-7.

4. Joel JJ, Jose N, Shastry CS. Patterns of Skin Disease and Prescribing Trends in Rural India. Sch Acad J Pharm. 2013;2(4):304-9.

5. Saravanakumar R. Study of prescribing pattern of topical corticosteroids in the department of dermatology in multi-specialty tertiary care teaching hospital in south India. Inj $\mathbf{J}$ Res Pharm Sci. 2012;3(4):685-7.

6. Saha A, Das NK, Hazra A, Gharami RC, Chowdhury SN, Datta PK. Cutaneous adverse drug reaction profile in a tertiary care out patient setting in eastern India. Indian J Pharmacol. 2012 Nov;44(6):792.

7. Gohel D, Bhatt SK, Malhotra S. Evaluation of Dermatological Adverse Drug Reaction in the Outpatient Department of Dermatology at a Tertiary Care Hospital. Ind J Pharm Pract, 2014;7(3):42-9.

8. Nandha R, Gupta A, Hashmi A. Cutaneous adverse drug reactions in a tertiary care teaching hospital: A North Indian perspective Int J Appl Basic Med Res. 2011 Jan-Jun;1(1):50-3.

9. Sushma M, Noel MV, Ritika MC, James J, Guido S. Cutaneous adverse drug reactions: a 9-year study from a South Indian Hospital. Pharmacoepidemiol Drug Saf. 2005;14:567-70.

10. Pudukadan D, Thappa DM. Adverse cutaneous reaction: clinical pattern and causative agents in a tertiary care centre in South India. Ind J Dermatol Vereeol Leprol. 2004;70:20-4.
11. James J, Sushma M, Gudio S, Elizabeth J. Cutaneous Adverse Drug Reactions in a South Indian Tertiary Care Centre. Ind J Deramtol. 2005;50:17-21.

12. Lamani VL, Ratnakar JS, Kotinatot BC, Bhushan A. Study of cutaneous adverse drug reactions in a tertiary care teaching hospital. Int J Basic Appl Med Scienc. 2015:5(1).

13. Verma R, Tiwari S, Gupta CM, Verma N. Cutaneous adverse reactions -a study of clinical patterns casuality, severity, and preventability. IOSR. J Dent Med Scienc. 2014;13(7):2279-0861.

14. Naldi L, Conforti A, Venegoni M, Troncon MG, Caputi A, Ghiotto E, et al. Cutaneous reactions to drugs. An analysis of spontaneous reports in four Italian regions. Brit J Clin Pharmacol. 1999 Dec 1;48(6):839-46.

15. Borah A, Lahkar M, Singha B, Lihite RJ, Hazarika D. To study the pattern of suspected adverse drug reactions in patients coming to the department of dermatology in Gauhati Medical College and Hospital, Guwahati, Assam, India. Int J Basic Clin Pharmacol. 2016;5:1655-9.

Cite this article as: Kishore MS, Konnur SS. A study on drug induced cutaneous adverse drug reactions at a tertiary care hospital, Mysore, India. Int J Basic Clin Pharmacol 2019;8:777-81. 